\title{
Moving on from the
}

\section{'coups and \\ quakes' mode}

\section{After the Tsunami: Crisis Communication in Finland and Sweden, edited by Ullamaija Kivikuru and Lars Nord. Gothenberg: Nordicom, University of Gothenberg, Sweden, 2009, 219 pp. ISBN 978-91-89471-85-6.}

DOTENTIAL turning-points in the rapid development of journalism around the turn of the $21 \mathrm{st}$ century have necessarily come thick and fast. Substantial claims can be made for a number of major pivotal moments - the Columbine shootings (blogging), the 7/7 attacks in London (user-generated content) and the Sichuan earthquake or Mumbai bombings (social networks). Coverage of the Indian Ocean tsunami marked a temporal central point in a dynamic decade (1999-2009), and exhibited to varying degrees all of the characteristics of the changing landscape of journalism.

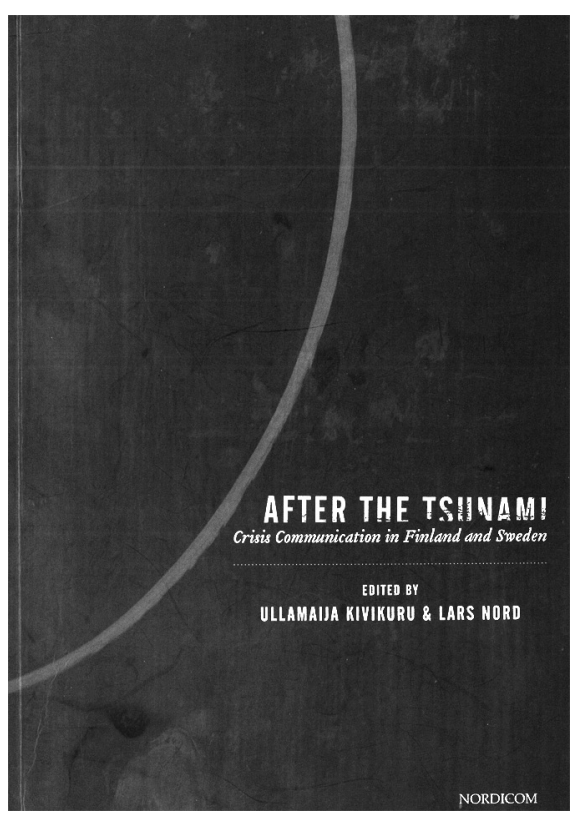

On the one hand, the scale and extent of the event prompted saturation and global 24/7 media coverage, while, on the other hand, individuals and groups of ordinary citizens used the so-called new media to overcome the limitations of orthodox journalistic performance, just as journalists and news organisations wrestled with their functional capacity. This collection of essays is primarily focused, as the sub-title of the volume indicates, on crisis communication in two specific countries; but it is inherent in the nature of the events of December 2004 that they defy such reductionism. Sweden and Finland provide a starting-point, rather than an 
end-point, for the analyses simply because although they were 'geographically non-impacted countries' (that is, the tsunami did not occur in either), the consequence for both were huge.

The tsunami represented the largest peace-time disaster in Finland's history, and, measured in the deaths of Swedes, was equivalent to the 1994 Estonian ferry disaster. Finland and Sweden, then, stand as proxies for the global and transnational nature of both the event and its mediation. No doubt those chapters which focus on the specificities of political communication, rhetorical strategies, crisis management and journalism in Finland and Sweden have much to say which is relevant beyond the geographical and cultural boundaries of those particular countries. However, it is the chapters which directly address the wider contexts of mediation and journalism which have greatest immediate relevance.

To some extent, as most of the authors point out, the nature of the Indian Ocean tsunami shaped its mediation. The simple scale and scope of the tsunami (13 countries hit, 286,000 deaths, or ten times the toll of 9/11), its political (Asian) and economic (tourism) salience, its amenability to domestication (victims from many nations), the availability of utilitarian technologies (digital image capture and transmission) and the investment in non-stop global media (CNN, BBC and many others) combined to produce both a global media event and transnational mediation. Yet these were perhaps triggerpoints which activated journalisms already transforming in response to altered socio-cultural conditions.

Mervi Pantti considers the evidence of 'cosmopolitan sensibilities' in the coverage of the Finnish press ( $p$. 83). She argues that mediation tapped into a public willingness, arising in part out of the experiences of travel, to support humanitarian aid on the basis of a feeling of a shared human condition which elided differences of Other (pp. 95-7). Similarly, Letukas, Olofsson and Barnshaw, in examining the creation of social solidarity, point out that one of the traits of the media coverage of the disaster was the collapsing of many nationalities into a single global humanity (p. 113).

What concerns these authors, and Hellman and Riegert, who contribute a chapter comparing the coverage of CNN and the Swedish TV4, is the genuineness of these responses. Pantti reminds us that humanitarian aid is most often a zero-sum game: as the media drew attention to the tsunami, it drew it away from other equally needy causes (p. 84). Letukas, Olofsson and Barnshaw make the point that 
social and cultural proximity is most often constructed on a narrow, nativist basis (p. 112), and Hellman and Reigert argue that 24/7 transnational news-making, with its high dependence on speedy, episodic, ambiguous, image-driven coverage, may actually militate against establishing proximity (p. 145).

The sheer volume of journalistic coverage may veil its nature. As the editors suggest in their introduction, a widespread dissatisfaction with 'traditional news journalism', which may only be enhanced by its ubiquity, is driving many users both to alternative platforms and sources and to alternative modes of creation (pp. 10-11). Moreover, the absence of even the most incidental of elements (such as digitally-generated images of the earthquake in Pakistan) appears to very easily undermine the idea of human solidarity.

These studies usefully map much of the contemporary condition of journalism but ultimately they are broadly inconclusive. What emerges is a picture of journalism caught in the vice of socio-cultural change (cosmopolitanism, 'we media') and media manoeuvring for self-preservation (transnational, 24/7 news), both jaws of which still have to negotiate a residual nativism. It will be instructive to compare in due course the mediation of the tsunami with that of the earthquake in Haiti in 2009, which was similar in scale but perhaps significantly different in many other crucial respects.

This might provide a more reliable test of whether journalism has moved on-finally-from its 'coups and earthquakes' mode. 